\title{
POLÍTICAS PÚBLICAS PARA EDUCAÇÃO SUPERIOR E CRIAÇÃO DE NOVAS IFES: REVISÃO SISTEMÁTICA ${ }^{1}$
}

Francisco João de Deus de Carvalho²

Alcides Leão Santos Júnior ${ }^{3}$

0 objetivo deste trabalho é apresentar evidências científicas disponíveis na literatura sobre a relação entre as políticas públicas para a educação superior, do início do século XXI, e a implantação de novas instituições federais de ensino superior (Ifes)/campi no Brasil. Para isso, foram buscados artigos nas bases de dados Scielo.br, Portal de Periódicos Capes e Web of Science, publicados entre 2003 e 2016, sendo quatro estudos incluídos nesta revisão sistemática. Aponta-se que a criação de uma estrutura universitária é resultado do aumento de egressos do ensino médio e das exigências do mercado de trabalho, mas, sobretudo, é uma decisão política que envolve um coletivo. Além disso, para os locais antes desassistidos de educação superior, as Ifes trazem inúmeros benefícios para os sujeitos, o local e a região.

Palavras-chave: educação superior; políticas públicas; instituições de ensino superior.

\section{PUBLIC POLICIES FOR HIGHER EDUCATION AND NEW CREATION IFES: SYSTEMATIC REVIEW}

The aim of this paper is to present scientific evidence available in the literature on the relationship between public policies for higher education, the beginning of the century, and the implementation of new Ifes/campus in Brazil. For this, they were searched articles in Scielo.br databases, Portal Periódicos Capes and Web of Science, published between 2003-2016, four studies included in this systematic review. It points out that the creation of a university structure is a result of the increase in high school graduates and the demands of the labor market, but above all is a political decision that involves a collective. In addition, for local unassisted higher education, Ifes bring numerous benefits to the subject, to the place and the region.

Keywords: higher education; public policy; higher education institutions.

\section{POLÍTICAS PÚBLICAS PARA LA EDUCACIÓN SUPERIOR Y LA CREACIÓN IFES NUEVAS: REVISIÓN SISTEMÁTICA}

El propósito de este trabajo es presentar la evidencia científica disponible en la literatura sobre la relación entre las políticas públicas para la educación superior, el comienzo del siglo, y la implementación de nuevas Ifes/campus en Brasil. Para esto, fueron artículos en las bases de datos Scielo.br, Portal Periódicos Capes y Web of Science, publicados entre 2003-2016, buscaron cuatro estudios incluidos en esta revisión sistemática. Se señala que la creación de una estructura universitaria es el resultado del aumento de los graduados de secundaria y las demandas del mercado de trabajo, pero sobre todo es una decisión política que implica un colectivo. Además, para la educación superior sin ayuda locales, las Ifes aportan numerosos beneficios para el sujeto, en el lugar y la región.

Palabras clave: educación superior; políticas públicas; las instituciones de educación superior.

1. DOI: http://dx.doi.org/10.38116/ppp55art1

2.Administrador no Instituto Federal de Educação, Ciência e Tecnologia da Paraíba (IFPB).E-mail: <joaodeus18@hotmail.com>. 3. Professor do Departamento de Educação da Universidade do Estado do Rio Grande do Norte (UERN). E-mail: <santosjunioralcides@gmail.com>. 


\section{POLITIQUES PUBLIQUES POUR L'ENSEIGNEMENT SUPERIEUR ET NOUVELLE CREATION IFES: REVUE SYSTEMATIQUE}

Le but de cet article est de présenter des preuves scientifiques disponibles dans la littérature sur la relation entre les politiques publiques pour l'enseignement supérieur, le début du siècle, et la mise en œuvre de nouveaux Ifes/campus au Brésil. Pour cela, ils ont été fouillés articles dans des bases de données Scielo.br, Portal Periódicos Capes et Web of Science, publiés entre 2003-2016, quatre études incluses dans cette revue systématique. II souligne que la création d'une structure universitaire est le résultat de l'augmentation des diplômés du secondaire et les exigences du marché du travail, mais surtout est une décision politique qui implique un collectif. En outre, pour l'éducation sans aide locale plus élevée, I'Ifes apportera de nombreux avantages à l'objet, à l'endroit et de la région.

Mots-clés: enseignement supérieur; public policy; établissements d'enseignement supérieur.

JEL: 123; I28; H52.

\section{INTRODUÇÃO}

A partir do último quartel do século XX, as políticas públicas desenvolvidas em diversas áreas foram formuladas seguindo os ideais neoliberais. Tal modelo, na busca por se tornar hegemônico, apoiou-se, e ainda se apoia, na máxima "menos Estado e menos políticas". Ele foi implantando na grande maioria dos países, e de forma acentuada também na América Latina, pregando um Estado mínimo, um forte ajuste fiscal, e a progressiva cessão de empresas e serviços públicos para o setor privado (Brandim e Feldmann, 2015).

Apoiadas nessa linha de pensamento e ação, as políticas públicas para a educação, principalmente para a educação superior, foram relegadas para segundo plano. Principalmente as universidades enfrentaram graves problemas, visto que passaram a ser vistas como "gasto excessivo", o que resultou em um quadro de retração e sucateamento. As vagas nas instituiçóes privadas aumentaram em $241,90 \%$ entre 1995 e 2002, enquanto o setor público aumentou somente $65,79 \%$ no mesmo período, e o país alcançou o maior índice de privatização da América Latina, ficando entre os cinco primeiros no ranking mundial de privatizaçóes (Cunha, 1997; Sleutjes, 1997; Sguissardi, 2005; 2006; Carvalho, 2006; Lucchesi, 2007; Ésther, 2014; Filardi e Padim, 2015; Inep, 2016).

Apesar disso, no início do século XXI, Luís Inácio Lula da Silva (2003-2010) foi eleito presidente da República, gerando muita expectativa em torno de mudanças no quadro de submissão do país à agenda neoliberal. Acreditava-se que a assunção de um governo de esquerda ao poder iria pôr fim à dominação da agenda anterior e instaurar um novo período. Alguns autores até chegam a denominar o período de governo pós-neoliberal (Sader, 2013). 
Apesar de pregar uma ideologia contrária ao que vinha sendo implantado no país pelos governos anteriores, é visível, nos primeiros anos de mandato de Lula, certa complementaridade às reformas iniciadas pelo presidente anterior, Fernando Henrique Cardoso (1995-2002). Ainda que com menos intensidade quanto aos ataques às necessidades das classes trabalhadoras, permanece a fundamentação das políticas sobre as recomendaçôes dos organismos financeiros internacionais, bem como a fragmentação do texto legal no que diz respeito à educação superior. As grandes mudanças só vieram no seu segundo mandato. Isso explica porque, entre 2003 e 2006, as instituições de ensino superior (IES) privadas continuam sua expansão $(22,40 \%)$ em relação às públicas, que cresceram apenas 19,8\%. Assim, inicialmente o governo volta suas ações para a sustentação financeira dos estabelecimentos que já existem - por meio do Programa Universidade para Todos (Prouni) e a continuação do Fundo de Financiamento ao Estudante do Ensino Superior (Fies) - e inicia a criação de algumas novas instituições federais de ensino superior (Ifes), com foco na interiorização dessa etapa de ensino (Programa Expansão I). Porém, a taxa de crescimento das IES privadas passou a ser menor no segundo mandato de Lula, quando cresceram 3,35\% (2007-2010), enquanto as públicas aumentaram em 11,65\% (Carvalho, 2006; Ésther, 2014; Barros, 2015; Brandim e Feldmann, 2015; Inep, 2016).

O Programa Expansão I é lançado em 2003 para atender às metas do Plano Nacional de Educação (PNE), período 2001-2010, com o objetivo de promover a interiorização do ensino superior público, e com foco voltado para as necessidades e vocaçôes econômicas de cada região do país. Como resultado, conforme Sguissardi (2006), até 2006, há a criação das seguintes universidades federais: Universidade Federal do ABC (UFABC); Universidade Federal do Recôncavo da Bahia (UFRB); Universidade Federal do Triângulo Mineiro (UFTM); Universidade Federal da Grande Dourados (UFGD); Universidade Federal de Alfenas (Unifal-MG); Universidade Federal Rural do Semi-árido (Ufersa); Universidade Federal dos Vales do Jequitinhonha e Mucuri (UFVJM); e Universidade Tecnológica Federal do Paraná (UTFPR).

Em 2008, é instituído um novo programa, o Programa de Apoio a Planos de Reestruturação e Expansão das Universidades Federais (Reuni), com o objetivo de ampliar o acesso e a permanência na educação superior, no nível de graduação, pelo melhor aproveitamento da estrutura física e dos recursos humanos já existentes nas Ifes. Dessa forma, juntos, o Programa Expansão I e o Reuni foram responsáveis, até 2010, pela criação de catorze novas universidades federais - além das já mencionadas, foram criadas ainda a Universidade Federal da Fronteira Sul (UFFS), a Universidade Federal do Oeste do Pará (Ufopa), a Universidade Federal da Integração Latino-Americana (Unila), a Universidade da Integração Internacional da Lusofonia Afro-Brasileira (Unilab), a Universidade Federal do Pampa (Unipampa), 
e a Universidade Federal de Ciências da Saúde de Porto Alegre (UFCSPA) - e de 126 novos campi universitários (Carvalho, 2006; Brasil, 2007; Gentili e Oliveira, 2013; Inep, 2016).

Após 2011, o governo de Dilma Rousseff (2011-2016) deu continuidade aos projetos e programas anteriores, e, especificamente na educação superior, prosseguiu com a expansão de vagas oferecidas por meio do Sistema de Seleção Unificado (Sisu), do Fies e do Prouni, e com o aumento de número de campi e cursos das Ifes. O número de IES públicas, entre 2011 e 2014, continuou crescendo (4,93\%), enquanto o de instituiçóes privadas reduziu em $0,53 \%$ (de 2.081 instituiçóes, em 2011, para 2.070, em 2014). No entanto, mesmo assim, em 2014, 75\% das matrículas da graduação ainda se concentravam no segmento privado (Inep, 2016). Cabe apontar ainda, nesse governo, a criação de mais quatro novas universidades federais: Universidade Federal do Cariri (UFCA), no Ceará (CE); Universidade Federal do Sul e Sudeste do Pará (UNIFESSPA); Universidade Federal do Oeste da Bahia (Ufob); e Universidade Federal do Sul da Bahia (UFSB).

Tais políticas implementadas após 2003 buscaram atender, entre outros, ao objetivo de minimizar os mencionados efeitos do legado de esquecimento e abandono das décadas anteriores, e estender a educação superior a uma maior parcela da população. Mais ainda, constituindo-se como políticas transversais, levaram investimentos para áreas interiorizadas do país, atendendo a demandas de locais/ regiôes antes desassistidos.

Mesmo diante dos avanços visíveis, Pereira e Silva (2010) afirmam que ainda não é possível definir esse processo como um movimento de democratização do ensino superior brasileiro. Seria necessário um conjunto de outras políticas sociais que promovessem condiçóes igualitárias de acesso e permanência, principalmente para os que estão à margem da sociedade. Barros (2015) também aponta que, apesar de valiosas, as iniciativas ainda são tímidas e demandarão muitas décadas até que se reduza o enorme deficit educacional no Brasil. Ainda se necessita de açóes mais efetivas também na educação básica, pois, somente assim, uma maior mobilidade profissional e social será propiciada.

Apesar das controvérsias quanto à democratização e à expansão com qualidade, é possível apontar uma tendência à massificação da educação superior, por meio da interiorização, bem como a ampliação das possibilidades de emprego público de boa qualidade e as possibilidades econômicas locais. Essa expansão seria uma aposta no lugar privilegiado da educação como estratégia para a promoção do desenvolvimento regional, da inclusão, da redistribuição de capitais (educacionais, empreendedores, simbólicos e legais) e do empoderamento societal. Talvez, estaria em curso, nas políticas públicas brasileiras, uma nova forma de desenvolvimentismo, no entanto com objetivos e estratégias distintos do modelo clássico desenvolvimentista (Marques e Cepêda, 2012; Araújo, 2013). 
Além disso, Pereira e Silva (2010) apontam a emergência de uma relação entre os movimentos sociais, o poder público, os servidores e os discentes, por meio de ações de ensino, pesquisa e extensão, criando-se redes. O processo de criação de novas Ifes e novos campi de Ifes já existentes envolve todo um conjunto de atores, por meio de estudos socioeconômicos e audiências públicas, na definição de cursos e na implantação de instituições (Ferreira, 2010). Portanto, a criação e/ou expansão não ocorre ao acaso, tendo em vista que toda política pública é resultado de uma decisão, e é permeada por disputas em torno de ideias e interesses; nesse contexto, há diversos atores envolvidos que disputam espaço na sua constituição e possuem demandas diferentes. Inclusive há demandas do local e consequências para aqueles que serão afetados, como também para o próprio espaço (Brito, 2014).

A investigação da idealização, criação e instalação dessas novas estruturas universitárias é necessária e essencial para desvendar e explicitar interesses, mas também para oportunizar a visibilidade dos protagonistas que lutaram pela implantação, bem como para registrar suas atuaçóes e participaçôes no processo de implantação. E alguns estudos têm se detido na análise destes processos. Assim, é nesse sentido que este artigo se propõe a apresentar as evidências científicas disponíveis na literatura que tratam sobre a relação entre as políticas públicas para a educação superior federal brasileira, implementadas no início do século XXI, e a implantação das novas Ifes ou dos novos campi.

\section{METODOLOGIA}

No intuito de alcançar o objetivo proposto nesta revisão sistemática, foi realizado um levantamento da produção, que trata da implantaçáo de novas Ifes ou novos campi a partir da implementação das políticas públicas para a educação superior federal traçadas no período 2003-2016. Para isso, foram utilizados os seguintes descritores, indexados em português no Thesaurus Brasileiro da Educação, com os respectivos vocábulos também em espanhol e inglês: educação superior; ensino superior; instituiçóes de ensino superior; políticas públicas; política governamental; política universitária; interiorizaçáo do ensino superior; expansão do ensino superior; criação da instituição de ensino; educación superior, instituciones de educación superior; políticas públicas; política del gobierno; política de la universidad; internalización de la educación superior, expansión de la educación superior; creación de la institución educativa; higher education; higher education institutions; public policies; government policy; university policy; internalization of higher education; expansion of higher education; e creation of the educational institution. As buscas realizadas filtraram artigos apenas nos idiomas português e espanhol, publicados entre 2003 e 2016. Além disso, também foram realizadas pesquisas adicionais nas referências dos artigos selecionados, porém não foi identificado nelas nenhum artigo que atendesse ao objetivo desta revisão. 
No processo de seleção dos artigos, os seguintes critérios de inclusão foram adotados: i) artigos completos; ii) publicados entre 2003 e 2016; iii) estudos realizados no Brasil; iv) publicados em português ou espanhol; e v) relacionados à criação de novas Ifes ou implantação de novos campi de Ifes existentes.

Os critérios de exclusão escolhidos foram: i) artigos publicados antes de 2003; ii) estudos realizados em outros países; iii) artigos puramente teóricos ou revisóes de literatura; iv) relacionados às IES estaduais, municipais, confessionais, comunitárias, filantrópicas ou privadas; e v) relacionados às políticas de açôes afirmativas (cotas), de avaliação institucional, ou de bolsas de estudo no setor privado.

A busca pelos artigos científicos foi realizada entre 12 de setembro e 6 de outubro de 2016, nas bases de dados Web of Science, Scielo.br e Portal de Periódicos Capes. A estratégia de pesquisa baseou-se na inserção de um conjunto de termos (strings) nas caixas de busca das bases, filtrando o idioma e o período de publicação, conforme critérios de inclusão e exclusão mencionados anteriormente. As strings foram construídas utilizando o operador booleano $A N D$, sendo elas:

- $\quad$ políticas públicas $A N D$ instituiçóes de ensino superior $A N D$ educação superior;

- política governamental $A N D$ instituiçóes de ensino superior $A N D$ educação superior;

- políticas públicas $A N D$ instituiçóes de ensino superior $A N D$ ensino superior;

- política governamental $A N D$ instituiçóes de ensino superior $A N D$ ensino superior;

- política universitária $A N D$ instituiçóes de ensino superior;

- expansão do ensino superior $A N D$ instituiçóes de ensino superior;

- interiorização do ensino superior $A N D$ instituiçóes de ensino superior;

- criação da instituição de ensino;

- políticas públicas AND instituciones de educación superior AND educación superior;

- política del gobierno AND instituciones de educación superior AND educación superior;

- politica de la universidad AND instituciones de educación superior;

- expansión de la educación superior AND instituciones de educación superior,

- internalización de la educación superior AND instituciones de educación superior; 
- creación de la institución educativa;

- public policies AND higher education institutions AND higher education;

- government policy AND higher education institutions AND higher education;

- university policy AND higher education institutions;

- expansion of higher education AND higher education institutions;

- internalization of higher education AND higher education institutions; e

- creation of the educational institution.

Todos os dados dos estudos encontrados foram organizados em uma planilha, para identificação das duplicações e leitura inicial dos títulos. Na primeira fase, foram achados 1.338 artigos, distribuídos nas bases de dados da seguinte forma: Web of Science $(105=7,85 \%)$, Sielo.br $(514=38,41 \%)$ e Portal Periódicos Capes $(719=53,74 \%)$.

\section{DISCUSSÃO DOS RESULTADOS}

Dos 1.338 artigos científicos encontrados, 566 foram excluídos por duplicação nas três bases de dados; outros 577, após a leitura dos títulos; e 178, após a leitura dos resumos. Dessa forma, dezessete artigos foram lidos na íntegra. Destes, treze foram excluídos pelos seguintes motivos: i) um artigo se referia à criação de uma Ifes - Universidade Federal Fluminense - antes de 2003 e, portanto, fruto de políticas públicas anteriores às que se discutem neste estudo; ii) um artigo se tratava puramente de revisão de literatura de pesquisa em andamento; e iii) os outros onze não tratavam da criação de novas Ifes/novos campi. Portanto, quatro estudos foram selecionados e incluídos nesta revisão sistemática, conforme figura A.1 do apêndice A. Todos os quatro estudos foram lidos mais de uma vez para, a partir daí, iniciar a extração dos dados necessários ao alcance do objetivo proposto.

Percebeu-se que todos $(\mathrm{n}=4)$ são estudos descritivos, apoiados sobre revisão de literatura e pesquisa documental. No entanto, o artigo de Barreto, Chacon e Nascimento (2012) também realizou coleta e tratamento de dados do Instituto Nacional de Estudos e Pesquisas Educacionais Anísio Teixeira (Inep) durante o período 2002-2009, e Mohr et al. (2012) fizeram levantamento com docentes e discentes, e consulta às fichas de matrículas na instituição estudada.

Apesar de possuírem objetivos diferentes, os estudos analisados têm em comum a descrição do processo de criação e/ou implantação de uma nova Ifes ou novo campus, destacando aspectos diversos relacionados a tal processo, entre os quais: desenvolvimento sustentável, inovação institucional e curricular, democratização do 
acesso, e implicações para os sujeitos, o local e o regional. E é visível a importância dos diversos atores nesse processo, principalmente dos agentes governamentais e dos movimentos sociais.

Cabe ressaltar, antes de iniciar a descrição dos estudos, que a maioria dos autores pertence às instituiçóes estudadas, à exceção de José Eustáquio Romão, que discute a criação da UFFS, contudo pertence ao Instituto Paulo Freire, e de João Costa de Oliveira, que também estuda a UFFS, mas é professor da rede estadual de ensino do Paraná (PR).

Barreto, Chacon e Nascimento (2012) abordaram a expansão da oferta de vagas na rede de ensino superior, com foco na Regiáo Metropolitana (RM) do Cariri, no interior do CE, no período 2002-2009. Para isso, trataram da implantação e da expansão de quatro IES (duas públicas e duas privadas) em Juazeiro do Norte e no Crato. Porém, conforme já definido nos critérios de inclusão e exclusão na seção 2, a análise aqui realizada deter-se-á apenas ao processo que ocorreu a partir da expansão da Universidade Federal do Ceará (UFC), via Reuni, quando em 2006 instalou o campus avançado de Juazeiro do Norte. Os dados que eles trazem das outras três IES não foram levados em consideração para esta análise.

Os autores partiram do pressuposto de que a educação, como via de acesso à informação, concorre para o processo de desenvolvimento sustentável, a partir do momento em que proporciona liberdade aos sujeitos. Elucidam, portanto, o aspecto humano e relacional da sustentabilidade. Dessa maneira, a expansão da educação superior, a partir do processo de capilarização nas cidades do interior dos estados, e especificamente na RM do Cariri, traz impactos diretos na vida das pessoas da região e indiretos para o entorno. A educação seria ferramenta para consolidação da inclusão das classes baixas e para a formação de um mercado consumidor socialmente comprometido. A ampliação das vagas e do acesso estaria relacionada aos ideais de desenvolvimento, igualdade social, liberdade e ampliação de oportunidades (Barreto, Chacon e Nascimento, 2012).

$\mathrm{O}$ artigo, porém, apesar de mencionar que a decisão pela criação do novo campus na RM do Cariri veio do Conselho Universitário da UFC, não elucida a participação de outros atores no processo de escolha do local onde se instalaria a nova estrutura. Dessa forma, fica uma lacuna, tendo em vista que a definição de políticas públicas para uma sociedade reflete os conflitos de interesses, os arranjos realizados entre os diversos atores tanto das instituiçôes estatais como da sociedade. Apesar dessa ausência, os autores abordam na sua conclusão que a RM do Cariri tem provado fortes investimentos públicos e privados, o que traz mudanças econômicas e sociais, que também são frutos de políticas públicas (Barreto, Chacon e Nascimento, 2012). 
Gomes e Vieira (2013), por sua vez, trataram do processo de criação e implementação da Unilab. Essa universidade, concebida como multicampi, foi criada em 2010, mas é fruto de movimentos e discussóes bem anteriores. Nasceu com a missão de construir uma ponte entre o Brasil e os países que falam português, principalmente aqueles do continente africano.

O cenário do início do século XXI é marcado pela estabilização econômica do país, pelo estímulo de iniciativas diversas de inclusão social e políticas afirmativas, e pela forte presença dos movimentos sociais, com destaque para o movimento negro brasileiro. A atuação de agentes políticos e dos movimentos sociais é marcante: inicialmente, a partir das negociações políticas para a escolha da sede (Redenção/ CE); posteriormente, pela criação da Comissão de Implantação da Unilab (2008), que, ao longo de dois anos, realizou levantamentos e estudos acerca de temas e problemas comuns ao Brasil e aos países parceiros nessa integraçáo. Além disso, pela atuação dos órgãos governamentais, por meio da doaçáo, pelas prefeituras, dos prédios para funcionamento dos campi em Redenção (CE), Acarape (CE) e São Francisco do Conde (Bahia), e pelo governo estadual, do terreno para construção do campus situado entre Redenção e Acarape (Gomes e Vieira, 2013).

Gomes e Vieira (2013) apontam que a Unilab estabelece vínculos com a realidade local e a promoção da cooperação internacional, no intuito de abrir espaço para o livre e amplo intercâmbio de conhecimento e cultura entre os países. Nesse contexto, concluem que a instituição vem cumprindo sua missão de construir a integração e a internacionalização em uma perspectiva acadêmica e solidária.

Romão e Loss (2014) discutiram a criação da UFFS como exemplo de inovação e superação de políticas históricas excludentes, e de alternativa de mudança e de inovação institucional e curricular. Nesse sentido, o destaque dado no artigo recai sobre a forte atuação dos movimentos sociais que integraram a rede de lutas pela construção de uma universidade popular.

Segundo os autores, a virada do milênio é um momento de crise, inclusive para a universidade, visto que o conhecimento tornou-se também a matéria-prima do atual estágio de acumulação capitalista. Mas ao mesmo tempo, no âmbito das políticas públicas, em atendimento ao PNE (2001-2010), estão sendo desenhadas políticas de expansão e interiorização da educação superior pública. Nesse contexto, os movimentos sociais da regiáo Sul, representados pela Via Campesina e pela Federação dos Trabalhadores na Agricultura Familiar da Região Sul (Fetraf-Sul), e as lideranças políticas e comunitárias se mobilizam para conseguirem a construção de uma IES pública e popular, aberta aos grupos sociais mais excluídos e comprometida com o desenvolvimento sustentável e solidário da regiấo, tendo como eixo a produção familiar e camponesa (Romão e Loss, 2014). 
O processo de discussão e amadurecimento foi longo para a definição da localização dos campi. Contudo, em 2011, a UFFS foi criada com o intuito de manter o diálogo entre os movimentos sociais e a comunidade acadêmica, preconizando a valorização do saber popular, visto que o modelo de universidade popular critica duramente o elitismo presente no modelo tradicional e o corporativismo existente na universidade brasileira. No entanto, mesmo após a implantação, o processo de discussão, negociação e estabelecimento de pactos mínimos tem se mostrado extremamente complexo, longo e de difícil construção de consensos, pois há: divergências entre os objetivos dos docentes e as demandas da comunidade e dos jovens estudantes; fortes disputas internas pelo poder; e resistência corporativista dos docentes, formados no modelo tradicional (europeu e norte-americano), conforme Romão e Loss (2014).

Os autores afirmam ainda que a presença do Conselho Estratégico Social da UFFS é a chave para o diálogo entre os diversos atores. Seria essa instituição um exemplo de uma nova direção que a educação superior mundial tem tomado, representada pelas universidades populares internacionais, em contraposição às Wold Class Universities (Romão e Loss, 2014).

Mohr et al. (2012) também têm por objetivo observar o processo de criação e consolidação da UFFS, mas, especificamente para a atuação do campus de Laranjeiras do Sul (PR), discutindo no fim aspectos relativos ao curso de licenciatura em educação do campo implantado na cidade. Porém, para os fins deste estudo, nos deteremos apenas às discussóes sobre a criação e a implantação da Ifes, sem adentrar nas discussóes relativas à criação do curso de graduação.

O contexto da época e da regiâo é de produção e reprodução da vida, com uma grande massa de jovens filhos de assentados sem perspectivas claras de futuro, em um campo transformado e minado pelas transnacionais do agronegócio, e uma população urbana cada vez maior, com problemas gradativamente desafiadores. Sendo assim, a instituiçáo traz a proposta de dispositivos de combate às desigualdades sociais e regionais. Além disso, Mohr et al. (2012) também dão o devido destaque ao papel das organizaçóes e dos movimentos sociais - estes também mencionados por Romão e Loss (2014) - desde as primeiras ideias e movimentaçôes até a oficializaçấo da universidade em 2009.

Os primeiros debates acerca da construção da universidade surgem ainda em 2005 no PR, entre os movimentos sociais e algumas prefeituras da região. A ideia era construir uma universidade popular, comandada por um coletivo. $\mathrm{E}$ aos poucos, o coletivo foi aumentando, inclusive a partir da fusão às mobilizaçóes que já aconteciam no Rio Grande do Sul e em Santa Catarina (SC) em prol de uma universidade pública federal para a região desassistida das Ifes existentes (Mohr et al., 2012). 
A articulação deu-se, portanto, com o coletivo local, responsável por acompanhar, coordenar e representar a regiáo no gerenciamento dos três estados, com a formação de coordenaçóes estaduais (pedagógica e política), e o envolvimento de vários setores da sociedade. Resultado disso foram as realizaçóes de seminários locais e um regional em Chapecó (SC), construindo a proposta a partir das necessidades regionais e dos programas federais recentes de expansão que o governo federal desenvolvia (Mohr et al., 2012).

Mohr et al. (2012) também destacam que a UFFS interfere radicalmente na dinâmica das regiōes em que se insere, tanto do ponto objetivo (questóes econômicas) quanto do subjetivo (a partir das mudanças no cenário artístico, intelectual, político e social). Assim, concluem que a instituição contribui para a correção do problema da baixa presença de estudantes oriundos do ensino público nas universidades estaduais e federais, promove a inclusão regional e geracional e reduz as desigualdades locais.

\section{CONCLUSÃO}

A partir do que foi apresentado, acerca dos quatro artigos analisados, é possível afirmar que o processo de criação de novas Ifes ou de campi de instituições já existentes, resultante da implementação de políticas públicas voltadas para a expansão e interiorização da educação superior brasileira nesse início de novo século, envolve não apenas os formuladores das políticas públicas, mas também um conjunto de outros atores. Entre estes, é visível nos artigos a menção à atuação dos movimentos sociais, das organizaçóes sociais, dos agentes políticos, dos entes das três esferas governamentais e da sociedade como um todo. Sendo assim, a criação de uma estrutura universitária é resultado do aumento da demanda exercida pela quantidade de egressos do ensino médio e pelas exigências do mercado de trabalho, mas, sobretudo é uma decisão política que envolve um coletivo.

Também é possível inferir que a implantação de Ifes em locais desassistidos de educação superior e, principalmente, marcados por graves problemas de ordem social, tais como a pobreza, o desemprego, o analfabetismo, a mortalidade infantil, entre outros, ocasiona enormes benefícios diretos e indiretos para o entorno. Os autores desses artigos apontam que o acesso à educação superior traz: a possibilidade de liberdade plena aos sujeitos como um dos aspectos para o alcance do pleno desenvolvimento sustentável; a ascensão social e econômica dos jovens das camadas mais carentes; o desenvolvimento econômico do local que recebe a instituição; a inclusão dos segmentos historicamente excluídos, como os pobres, os negros e os indígenas; a inclusão regional de cidades que não eram atendidas por nenhuma IES; e a inclusão geracional para aqueles que não tiveram acesso a esse nível de ensino na idade apropriada. 
Por fim, cabe destacar que este estudo se deteve em número reduzido de artigos $(n=4)$, sendo necessário estender as pesquisas na tentativa de localizar mais estudos que tratem dos processos históricos de implantação de IES, evidenciando os atores envolvidos, as demandas atendidas e as implicaçóes para os sujeitos e os locais que tiveram acesso à educação superior pública federal.

\section{REFERÊNCIAS}

ARAÚJO, T. B. Desenvolvimento regional brasileiro e políticas públicas federais no governo Lula. In: SADER, E. (Org.). 10 anos de governos pós-neoliberais no Brasil: Lula e Dilma. São Paulo; Rio de Janeiro: Boitempo; Flacso Brasil, 2013. p. 157-171.

BARRETO, P. L. N.; CHACON, S. S.; NASCIMENTO, V. S. Educação e desenvolvimento sustentável: a expansão do ensino superior na regiáo metropolitana do Cariri. Sustentabilidade em Debate, Brasília, v. 3, n. 1, p. 117-134, 2012. Disponível em: <https://bit.ly/3kGq519>. Acesso em: 6 out. 2016.

BARROS, A. S. X. Expansão da educação superior no Brasil: limites e possibilidades. Educaçáo e Sociedade, Campinas, v. 36, n. 131, p. 361-390, abr./jun. 2015. Disponível em: <https://bit.ly/2UO6zZz>. Acesso em: 28 jul. 2016.

BRANDIM, M. R. L.; FELDMANN, M. G. A reforma do ensino superior no contexto da reforma do estado brasileiro. Revista de Estudios e Investigación em Psicología y Educación, v. extra, n. 12, 2015. Disponível em: $<$ https://bit.ly/3nEaioV>. Acesso em: 28 jul. 2016.

BRASIL. Decreto no 6.096, de 24 de abril de 2007. Institui o Programa de Apoio a Planos de Reestruturação e Expansão das Universidades Federais (Reuni). Diário Oficial da União, Brasília, n. 79, p. 7, 25 abr. 2007. Seção1.

BRITO, L. C. A importância dos estudos sobre interiorização da universidade e reestruturação territorial. Espaço e Economia, ano 2, n. 4. 2014. Disponível em: <https://bit.ly/3nbtMB3>. Acesso em: 15 jul. 2016.

CARVALHO, C. H. Política para o ensino superior no Brasil (1995-2006): ruptura e continuidade nas relaçôes entre público e privado. In: REUNIÁO ANUAL DA ASSOCIAÇÃO NACIONAL DE PÓS-GRADUAÇÃO E PESQUISA EM EDUCAÇÃO, 29, 2006. Caxambu, Minas Gerais. Anais... Caxambu: Anped, 2006. Disponível em: <https://bit.ly/3f98Mbl>. Acesso em: 20 ago. 2016.

CUNHA, L. A. Nova reforma do ensino superior: a lógica reconstruída. Cadernos de Pesquisa, n. 101, p. 20-49, jul. 1997. Disponível em: <https://bit.ly/3lHcgnA>. Acesso em: 15 jul. 2016. 
ÉSTHER, A. B. Políticas de educação superior no Brasil, desenvolvimento econômico e inserção internacional. In: CONGRESSO IBERO-AMERICANO DE POLÍTICA E ADMINISTRAÇÃO DA EDUCAÇÃO, 4.; CONGRESSO LUSO BRASILEIRO DE POLÍTICA E ADMINISTRAÇÃO DA EDUCAÇÃO, 7, Porto, Portugal, 2014. Anais... Porto: Anpae, 2014. Disponível em: $<$ https://bit.ly/3lbsUf9>. Acesso em: 12 jul. 2016.

FERREIRA, T. Expansão para o interior: governo inicia processo de descentralizaçáo do ensino superior. Desafios do desenvolvimento, ano 7, ed. 58, fev. 2010. Disponível em <https://bit.ly/3eMcozO>. Acesso em: 13 mar. 2014.

FILARDI, A. M. B.; PADIM, D. F. Políticas públicas de expansão do ensino superior federal no Brasil no contexto da mundialização do capital. Revista HISTEDBR On-line, Campinas, n. 61, p. 403-415, mar. 2015. Disponível em: <https://bit.ly/2I9lH0V>. Acesso em: 12 jul. 2016.

GENTILI, P.; OLIVEIRA, D. A. A procura da igualdade: dez anos de política educacional no Brasil. In: SADER, E. (Org.). 10 anos de governos pós-neoliberais no Brasil: Lula e Dilma. São Paulo; Rio de Janeiro: Boitempo; Flacso Brasil, 2013. p. 253-262.

GOMES, N. L.; VIEIRA, S. L. Construindo uma ponte Brasil-África: a Universidade da Integração Internacional da Lusofonia Luso-Afrobrasileira (Unilab). Revista Lusófona de Educaçáo, n. 24, p. 75-88, 2013. Disponível em: $<$ https://bit.ly/3n6MoC8>. Acesso em: 6 out. 2016.

INEP - INSTITUTO NACIONAL DE ESTUDOS E PESQUISAS EDUCACIONAIS ANÍSIO TEIXEIRA. Sinopses Estatísticas do Censo da Educaçáo Superior - 2001 a 2014. Brasília: Inep, 2016. Disponível em: <https://bit.ly/3pCKRFR>. Acesso em: 9 jun. 2016.

LUCCHESI, M. A. S. Políticas públicas para a educação superior no Brasil no contexto sulamericano: convergências e transformaçôes na passagem do século. Revista Brasileira de Política e Administração da Educaçáo, v. 23, n. 3, p. 513-528, set./dez. 2007. Disponível em: <https://bit.ly/32qBsqU>. Acesso em: 12 jul. 2016.

MARQUES, A. C. H.; CEPÊDA, V. A. Um perfil sobre a expansão do ensino superior recente no Brasil: aspectos democráticos e inclusivos. Perspectivas, São Paulo, v. 42, p. 161-192, jul./dez. 2012. Disponível em: <https://bit.ly/2U8gKri>. Acesso em: 12 jul. 2016. 
MOHR, N. E. R. et al. A expansão das fronteiras da educação pública superior: uma análise da experiência da Universidade Federal da Fronteira Sul em Laranjeiras do Sul. Revista Brasileira de Estudos Pedagógicos, Brasília, v. 93, n. 235, p. 791817, 2012. Disponível em: <https://bit.ly/3n7VvCw>. Acesso em: 6 out. 2016.

PEREIRA, T. I.; SILVA, L. F. S. C. As políticas públicas do ensino superior no governo Lula: expansão ou democratização? Revista Debates, Porto Alegre, v. 4, n. 2, p. 10-31, jul./dez. 2010. Disponível em: <https://bit.ly/3lbuUnF>. Acesso em: 12 jul. 2016.

ROMÃO, J. E.; LOSS, A. S. A Universidade Popular no Brasil. Foro de Educación, v. 12, n. 16, p. 141-168, 2014. Disponível em: <https://bit.ly/3pbGt0s>. Acesso em: 6 out. 2016.

SADER, E. (Org.). 10 anos de governos pós-neoliberais no Brasil: Lula e Dilma. São Paulo; Rio de Janeiro: Boitempo; Flacso Brasil, 2013.

SGUISSARDI, V. Universidade pública estatal: entre o público e o privado mercantil. Educação e Sociedade, Campinas, v. 26, n. 90, p. 191-222, jan./abr. 2005. Disponível em: <https://bit.ly/3p8xPzG>. Acesso em: 10 ago. 2016.

. Reforma universitária no Brasil - 1995-2006: precária trajetória e incerto futuro. Educação e Sociedade, Campinas, v. 27, n. 96, p. 1021-1056, out. 2006. (Especial). Disponível em: <https://bit.ly/3kaQaIN>. Acesso em: 10 ago. 2016.

SLEUTJES, M. H. S. C. Uma avaliação estratégica da situação de crise e mudança das universidades federais brasileiras. 1997. 300 f. Dissertação (Mestrado) Fundação Getulio Vargas, Rio de Janeiro, 1997. 


\section{APÊNDICE A}

\section{FIGURA A. 1}

Fluxograma referente ao processo de seleção dos estudos
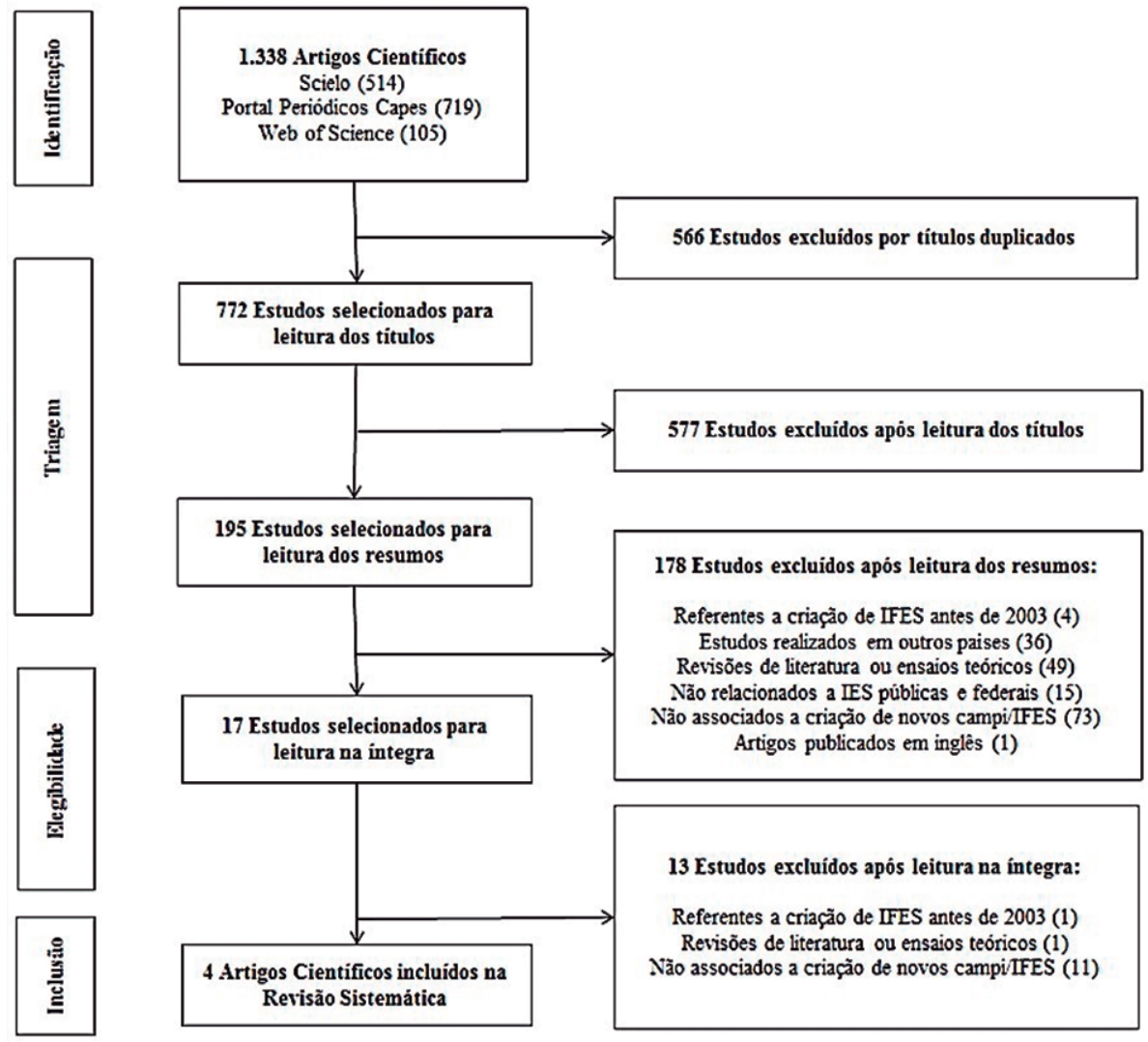

Elaboração dos autores.

Obs.: Figura reproduzida em baixa resolução e cujos leiaute e textos não puderam ser padronizados e revisados em virtude das condições técnicas dos originais (nota do Editorial).

Data da submissão: 20/3/2017

Primeira decisão editorial em: 4/10/2018

Última versão recebida em: 15/1/2019

Aprovação final em: 28/1/2019 
